Research Article

Yuan Yao, Ying Chen*, Jianyong Chen, and Yulie Gong

\title{
Comparative study of heat transfer enhancement on liquid-vapor separation plate condenser
}

https://doi.org/10.1515/phys-2020-0006

Received Nov 27, 2019; accepted Jan 14, 2020

\begin{abstract}
Basic structures of liquid-vapor separation cooling plates (LSCPs) and a liquid-vapor separation plate condenser (LVSPC) are innovatively designed. Strengthening heat transfer principle of the LSCPs is demonstrated by theoretical analysis. The average condensation heat transfer coefficients (ACHTCs) of the LSCPs are calculated and compared with conventional cooling plate (CCP). Results show that for a laminar flow, the ACHTCs of 2-parts liquid-vapor separation cooling plate and 3-parts liquid-vapor separation cooling plate are respectively $19 \%$ and $32 \%$ higher than the ACHTCs of the CCP in the same conditions. The ACHTC ratio of N-parts liquid-vapor separation cooling plates (NLSCP) to CCP is $\sqrt[4]{N}$ in the same conditions. For a turbulent flow, results show the smaller the height of condensation area, the greater the ACHTCs of cooling plate. In the LVSPC study, operation conditions include the refrigerant R134a mass flux ranging from 22 to $32 \mathrm{~kg} /\left(\mathrm{m}^{2} . \mathrm{s}\right)$ and inlet vapor quality from 0.5 to 1 for the saturated temperature of $40^{\circ} \mathrm{C}$. Calculation results showed that the ACHTCs of the LVSPC are $6-24 \%$ higher than the ACHTCs of the given common plate condenser (CPC), and similar to the CPC, the ACHTCs of the LVSPC increases with the increase of mass flux and vapor quality.
\end{abstract}

Keywords: liquid-vapor separation; plate heat exchanger; condensation heat transfer; numerical simulation

${ }^{\star}$ Corresponding Author: Ying Chen: School of Material and Energy, Guangdong University of Technology, Guangzhou 510006, China; Email: chenying_gut@126.com

Yuan Yao: School of Material and Energy, Guangdong University of Technology, Guangzhou 510006, China; Guangzhou Institute of Energy Conversion, Chinese Academy of Sciences, Guangzhou 510640, China; Key Laboratory of Renewable Energy, Chinese Academy of Sciences, Guangzhou 510640, China; Guangdong Provincial Key Laboratory of New and Renewable Energy Researchand Development, Guangzhou 510640, China

Jianyong Chen: School of Material and Energy, Guangdong University of Technology, Guangzhou 510006, China

Yulie Gong: Guangzhou Institute of Energy Conversion, Chinese Academy of Sciences, Guangzhou 510640, China; Key Laboratory of Renewable Energy, Chinese Academy of Sciences, Guangzhou

ə Open Access. ๑ 2020 Y. Yao et al., published by De Gruyter. (cc) BY License

\section{Symbols}

$\boldsymbol{D}_{h}$ hydraulic diameter $[\mathrm{m}]$

$\boldsymbol{G}$ mass flux $\left[\mathrm{kg} \cdot \mathrm{m}^{-2} \cdot \mathrm{s}^{-1}\right]$

$\boldsymbol{G}_{a}$ Galileo number

g gravitational acceleration $\left[\mathrm{m} \cdot \mathrm{s}^{-2}\right]$

$\boldsymbol{h}$ convective heat transfer Coefficient $\left[\mathrm{W} \cdot \mathrm{m}^{-2} \cdot \mathrm{K}^{-1}\right]$

$\boldsymbol{h}_{l}$ convective heat transfer coefficient of a laminar flow $\left[\mathrm{W} \cdot \mathrm{m}^{-2} \cdot \mathrm{K}^{-1}\right]$

$\boldsymbol{h}_{t}$ convective heat transfer coefficient of a turbulent flow

$\left[\mathrm{W} \cdot \mathrm{m}^{-2} \cdot \mathrm{K}^{-1}\right]$

$\boldsymbol{k}$ thermal conductivity $\left[\mathrm{W} \cdot \mathrm{m}^{-1} \cdot \mathrm{K}^{-1}\right]$

l characteristic length $[\mathrm{m}]$

$\boldsymbol{N}_{u}$ Nusselt number

$\boldsymbol{P}_{r}$ Prandtl number

$\boldsymbol{x}_{c}$ the height at the turning point where the laminar flow change into the turbulent flow $[\mathrm{m}]$

$\boldsymbol{R}_{e}$ Reynolds number

$\boldsymbol{t}$ Temperature $\left[{ }^{\circ} \mathrm{C}\right]$

$\boldsymbol{\mu}$ velocity $[\mathrm{m} / \mathrm{s}]$

$\boldsymbol{x}$ vapor quality

$\boldsymbol{\rho}$ Density $\left[\mathrm{kg} \cdot \mathrm{m}^{-3}\right]$

$\boldsymbol{\eta}$ Viscosity $[\mathrm{Pa} \cdot \mathrm{s}]$

$\lambda$ thermal conductivity $\left.\left[\mathrm{W} \cdot \mathrm{m}^{-1} \cdot \mathrm{K}^{-1}\right)\right]$

$r$ latent heat of vaporization $\left[\mathrm{J} \bullet \mathrm{kg}^{-1}\right]$

\section{Subscripts}

\author{
$l$ Liquid \\ g gas \\ s saturated \\ $\mathbf{w}$ wall \\ v Vertical cooling plate \\ m mean \\ eq equivalent
}

510640, China; Guangdong Provincial Key Laboratory of New and Renewable Energy Research and Development, Guangzhou 510640, China 


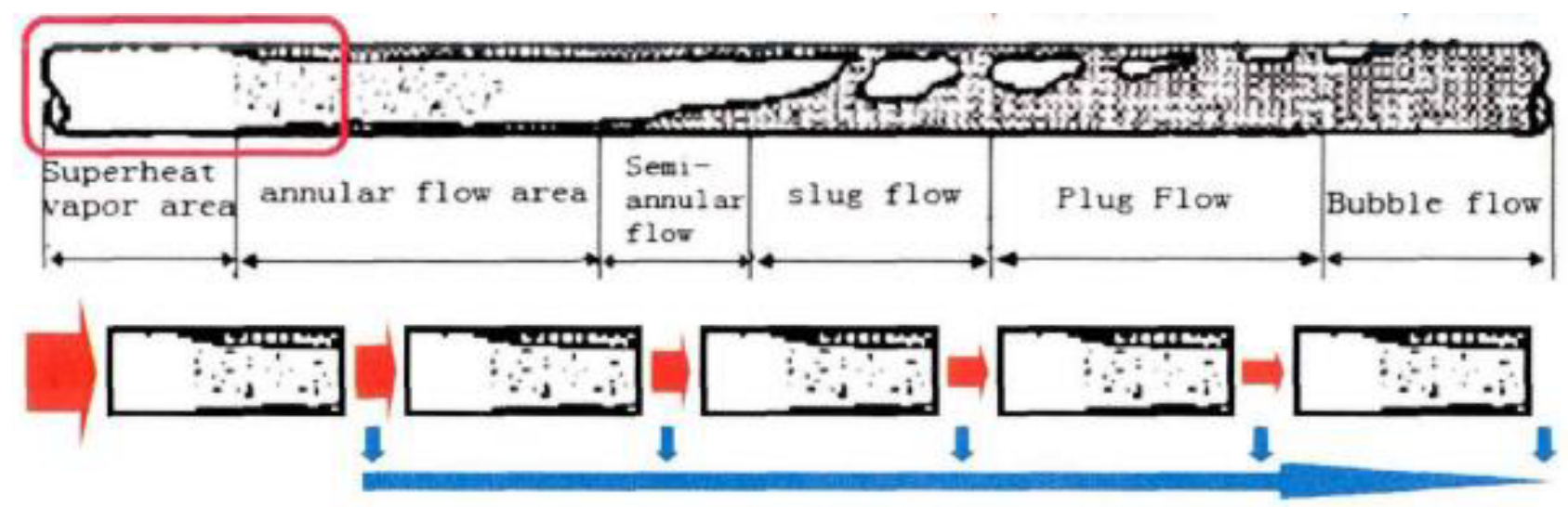

Figure 1: Schematic of liquid-separation technology applied to parallel tube condenser

\section{Introduction}

Condensers are widely used in many industries, such as petroleum, chemical, electric power, refrigeration, air conditioning and so on. Improving heat transfer performance of condensers is very important to increase efficiency of production equipments [1]. In recent years, liquid-vapor separation condensation has attracted the attention of some researchers as a new method of strengthening condensation heat transfer [2]. Figure 1 shows the schematic of liquid-vapor separation condensation in the direction of vapor flow in the horizontal tube, drain holes are arranged at intervals to separate the condensate in the tube in time, so that the two-phase flow in the tube can maintain annular flow which can keep the high-efficiency heat exchange state [3].

Current studies on the liquid-vapor separation condensation mainly include mechanism research of enhanced heat transfer, optimal design of condenser structure and improvement of system performance. Tan et al. [4] and Guo et al. [5] used CFD commercial software and VOF model to simulate the unsteady flow and liquid-vapor separation of R134a in a multi pass header. In the multi manifold structure of 5-in-3-out header, the design of separator hole can effectively improve the distribution uniformity of two-phase refrigerants in 3-out branch pipe compared with the design without hole. Mo et al. [6] found that the vapor flow rate, liquid flow rate and inlet pressure are all important factors affecting the efficiency of liquid-vapor separation. Hua et al. [7] proposed a computation program to predict the in-tube thermodynamic performance of the Liquid-vapor separation condenser (LSC) and used the Penalty Factor with the predicted results to optimize the refrigerant circuit of the LSC.
Some research results validated the high performance of an air-conditioning system with a liquid-vapor separation condenser. By comparing with the conventional condenser, Chen et al. [8, 9] studied the performance of the R22 refrigeration system with the LSC. Results show that the heat exchange area of the condenser is only $77 \%$ of that of the original system with the conventional condenser, and the refrigerant charge is reduced by $27 \%$ at the same cooling capacity. Zhong et al. [10] first applied the design principle of liquid-vapor separation condensation to the microchannel multi pass parallel flow condenser, and then experimentally studied the influence of the partition in the header on the performance of the heat exchanger. Experimental results show that when the refrigerant flow rate is greater than $590 \mathrm{~kg} \cdot \mathrm{m}^{-2} \cdot \mathrm{s}^{-1}$ or the average dryness is higher than 0.57 , the average heat transfer coefficient of the new microchannel condenser with liquid-vapor separation structure is improved by nearly $4 \%$, and the pressure drop is only $48.6 \%-69.5 \%$ of that of the conventional microchannel condenser. Zhong et al. [11] developed a new model to predict the heat transfer coefficient and pressure drop of double row microchannel heat exchanger, with the maximum prediction deviation of $25.6 \%$ and $20.8 \%$, respectively. Zhong et al. [12] compared the three heat exchangers by using three comprehensive evaluation indexes: pressure drop energy ratio, penalty factor and minimum entropy increase. The results show that the irreversibility of the condenser with liquid-vapor separation structure is the lowest and the comprehensive performance is the best. The pressure drop of the LSC greatly reduces by $30.5 \%-52.6 \%$ of the parallel-flow condenser. Chen et al. [13] compared an air conditioner having a baseline fin-and-tube condenser with an air conditioner having LSC. It was validated that both the cooling capacity and EER (Energy Efficiency Ratio) of the two systems were al- 


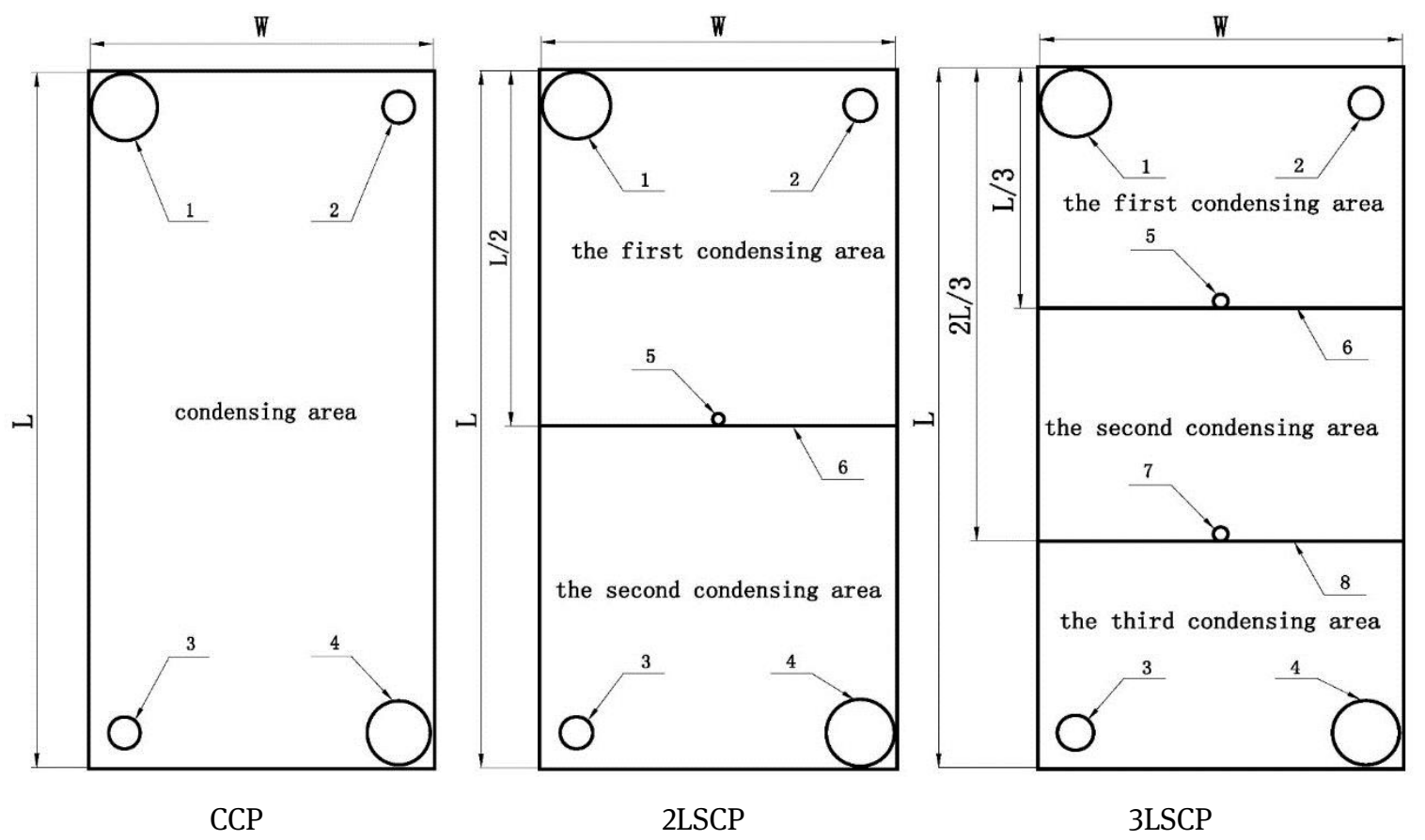

1. vapor inlet, 2. coolant outlet, 3. coolant intlet, 4. the third condensate outlet, 5. the first condensate outlet, 6 . the first condensate baffle, 7. the second condensate outlet, 8 . the second condensate baffle

Figure 2: Diagrammatic sketch of CCP, 2LSCP, 3LSCP

most the same with the LSC having just $67 \%$ of the heat transfer area of the baseline condenser. In addition, the LSC system was charged with only $80 \%$ of the refrigerant in the baseline system. Luo et al. [14] established the organic Rankine cycle mathematical model of the LSC and optimized the structure with the heat transfer coefficient, pressure drop and total cost as the optimization objectives. A solving strategy that integrates model relaxation, solver selection, and tube-pass scheme initialization is proposed by Luo et al. [15].

Although some progresses have been made in the research of liquid-vapor separation in tube heat exchangers, research on plate heat exchangers (PHE) is still unclear. PHE, which are characterized by high effectiveness of heat transfer and compactness, have been widely used. However, condensation heat transfer along the plate in a conventional plate condenser (CPC) is unavoidably worsened due to condensate accumulation. Furthermore, due to complicated phase-change heat transfer mechanism which involved many factors, PHE working as condensers need to be improved in structural design. In this paper, an attempt is made to investigate heat transfer enhancement in liquid-vapor separation plate condensers by theoretical calculations and comparison.

\section{Basic structure and principle}

In this paper, an innovative idea was introduced to design a new kind of vertical plate condensers. This kind of condenser can automatically separate liquid from vapor and drain the condensate in time from cooling plate through drain holes. This innovated condenser is actually one kind of liquid-vapor separation plate condensers (LVSPC). Compared with CPC, LVSPC decrease the thickness of the liquid film, reduce the thermal-conduction resistance, so LVSPC can improve evidently the phase change heat conductivity coefficient.

Because cooling plates are the heat exchange area in condensers, the research of heat transfer performance of LVSPC is mainly to study the heat transfer characteristics of the cooling plates. Two kinds of cooling plates with drain holes are designed in this paper. One is named twoparts liquid-vapor seperation cooling plate(2LSCP), the other is named three-parts liquid-vapor seperation cooling plate (3LSCP). Taking a conventional cooling plate (CCP), 2LSCP and 3LSCP as examples, this paper compared and studied the characteristics of liquid-vapor seperation cooling plates (LSCP). Diagrammatic sketches of the three kinds of cooling plates are shown in Figure 2.

CCP has only one condensate outlet, so the condensate cannot drain out until it flows to the plate bottom. 


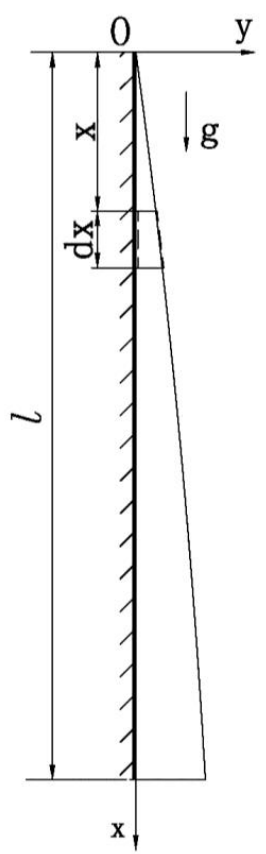

CCP

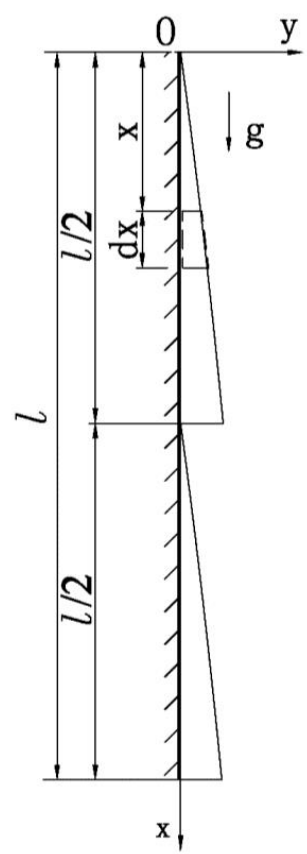

2LSCP

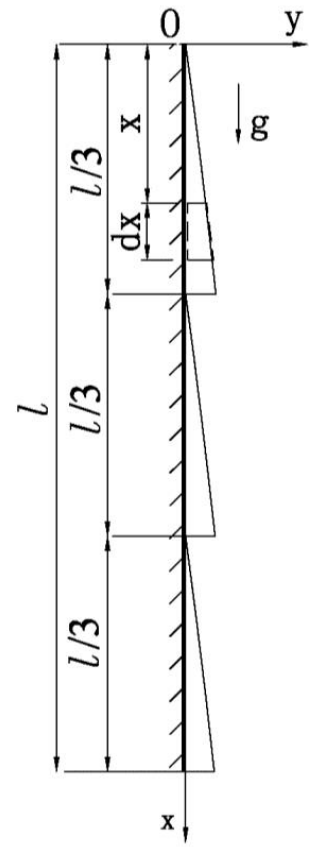

3LSCP

Figure 3: Schematics of condensate film on CCP, 2LSCP and 3LSCP

2LSCP has two condensate outlets. One is in the middle of the plate, and the other is in the bottom. The cooling plate is divided into two parts (the first condensing area and the second condensing area) by a condensate baffle which is under the first condensate outlet. During working, the vapor from the vapor inlet is condensed simultaneously in the first condensing area and the second condensing area. The condensate film in the two condensing area drops respectively to the baffle and bottom under the force of gravity, then drains out of the plate from the first condensate outlet and the second condensate outlet. In the same way, 3LSCP has three condensing areas and three condensate outlets, which enable the condensate drain out at the same time. Therefore, 3LSCP drains the condensate faster than 2LSCP, and 2LSCP drains the condensate faster than the CCP. The faster the drain speed is, the thinner the liquid film on the plate, and the smaller the thermal-conduction resistance, and the bigger the condensation heat transfer coefficient. So this is the basic principle of strengthening heat transfer of the LVSPC.

\section{Condensation heat transfer coefficient}

Figure 3 shows general schematics of condensate film on the three kinds of the cooling plates. The $\mathrm{x}$ axis indicates the direction of gravity and the y axis indicates the thickness direction of the condensate film. $l$ is the whole height of cooling plate. $l / 2$ is the height of the first condensing area (same as the second condensing area) of 2LSCP. Similarly, $l / 3$ is the height of each condensing area of 3LSCP. According to Figure 3, comparative calculations of the average condensation heat transfer coefficients (ACHTC) of these three kinds of cooling plates can be performed in the same condition. There are two flow states of the condensate film, laminar and turbulent flow. Reynolds number is usually used to determine flow states in engineering calculations. According to Nusselt [16], if $\operatorname{Re}<2300$, flow state can be considered laminar, if $\mathrm{Re}>2300$, flow state can be considered turbulent. There are different formulas for calculating the ACHTC in different flow states. Thus, theoretical calculations for the ACHTC of the three kinds of cooling plates must be performed in two situations, laminar flow and turbulent flow. 


\subsection{Laminar flow $(\operatorname{Re}<2300)$}

Based on boundary layer theory, the governing equations of motion and heat exchange of infinitesimal $\mathrm{dx}$ are established. After a series of integral transforms, an ACHTC formula can be obtained from the Nusselt theoretical solution of condensation inside a vertical plate for laminar liquid film flow as Eq. (1) [16]

$$
h_{v}=\frac{1}{l} \int_{0}^{l} h_{x} d_{x}=\frac{4}{3} h_{x=l}=0.943\left[\frac{g r \rho_{l}^{2} \lambda_{l}^{3}}{\eta_{l} l\left(t_{s}-t_{w}\right)}\right]^{1 / 4}
$$

where, $\eta_{l}, \lambda_{l}, \rho_{l}$, and $r$ represent the viscosity, thermal conductivity, density and latent heat of the liquid film, respectively; $t_{s}$ is the saturated temperature at the condensing pressure, $t_{w}$ is the wall temperature, and $x$ is the height of condensing area.

The analytic solution was obtained on the premise of making 8 hypotheses which ignore some subordinate effect factors. Although there is a deviation between the calculated result and the actual value, Eq. (1) is still an ideal and reliable formula for studying the ACHTCs of the cooling plates by the comparison method. When the ACHTCs of the above three cooling plates are respectively calculated by Eg. (1), under the same conditions, characteristic length $l$ is the only one variable which is different in the three calculations. The other variables, such as $\eta_{l}, \lambda_{l}, \rho_{l}, t_{s}$ and $t_{w}$, are the same in the three calculations. For the CCP, the total height of the plate, $l$, is the characteristic length. For the 2LSCP, because the height of the first condensing area is the same as the second condensing area, characteristic length of the two condensing area are the same $l / 2$. As a result, $l / 2$ is the characteristic length of 2LSCP. Similarly, $l / 3$ is the characteristic length of 3LSCP. The ACHTCs of the CCP, 2LSCP and 3LSCP can be contrasted as Eq. (2) and Eq. (3).

$$
\begin{gathered}
\frac{h_{v 2}}{h_{v 1}}=\frac{0.943\left[\frac{g r \rho_{l}^{2} \lambda_{l}^{3}}{\eta_{l} \frac{l}{2}\left(t_{s}-t_{w}\right)}\right]^{1 / 4}}{0.943\left[\frac{g r \rho_{l}^{2} \lambda_{l}^{3}}{\eta_{l} l\left(t_{s}-t_{w}\right)}\right]^{1 / 4}}=2^{1 / 4} \approx 1.19 \\
\frac{h_{v 3}}{h_{v 1}}=\frac{0.943\left[\frac{g r \rho_{l}^{2} \lambda_{l}^{3}}{\eta_{l}\left(\frac{1}{3}\left(t_{s}-t_{w}\right)\right.}\right]^{1 / 4}}{0.943\left[\frac{g r \rho_{l}^{2} \lambda_{l}^{3}}{\eta_{l} l\left(t_{s}-t_{w}\right)}\right]^{1 / 4}}=3^{1 / 4} \approx 1.32
\end{gathered}
$$

Where, $h_{v 1}, h_{v 2}$ and $h_{v 3}$ represent the ACHTCs of the CCP, 2LSCP and 3LSCP, respectively.

According to Eq. (2) and Eq. (3), it can be deduced that in the same conditions, the ACHTCs of the 2LSCP and 3LSCP are 19\% and 32\% higher than the CCP respectively. And so on, for a N-parts liquid-vapor separation cooling plate (NLSCP), the ACHTC ratio of the NLSCP to the CCP is $\sqrt[4]{N}$. Accordingly, for a vertical LSCP, the greater the number of condensing areas along the height direction, the higher the ACHTC of the LSCP. Because Eq. (1) indicate that $h v$ of a vertical cooling plate is inversely proportional to $\sqrt[4]{l}$, the ACHTC of a vertical cooling plate can be improved by reducing its characteristic length. Vapor-liquid separation is a good way to reduce the characteristic length of a cooling plate.

\subsection{Turbulent flow (Re>2300)}

For a turbulent liquid film, heat transfer of the laminar sublayer depends mainly on heat conduction, while the liquid film outside the laminar sublayer flow mainly transfers heat through convection, whose intensity of heat transfer is greatly increased. The ACHTC of the turbulent liquid film along a whole vertical plate can be obtained from the following formula:

$$
h=h_{l} \frac{x_{c}}{l}+h_{t}\left(1-\frac{x_{c}}{l}\right)
$$

where, $h_{l}$ and $h_{t}$ are the ACHTCs of the laminar flow and turbulent flow respectively, $x_{c}$ is the height at the turning point where the laminar flow change into the turbulent flow, and $l$ is the height of the whole plate. In accordance with Eq. (4), Labuntzov [17] developed an experimental correlation that can be used to calculate the ACHTC of a vertical cooling plate. The correlation is given by:

$$
N_{u}=G_{a}^{1 / 3} \frac{R_{e}}{58 P_{r s}^{(-1 / 2)}\left(\frac{P_{r w}}{P_{r s}}\right)^{1 / 4}\left(R_{e}^{3 / 4}-253\right)+9200}
$$

Where, $\mathrm{Nu}, \mathrm{Ga}, \mathrm{Re}, \mathrm{Pr}$ are Nusselt number, Galileo number, Reynolds number, Prandtl number, respectively. The value of Prw is determined by the plate temperature while other parameters are determined by the saturation temperature. All parameters are related to the condensate. The definition formulas of $N u, G a$ and $R e$ are $N u=h l / \lambda$, $G a=g l^{3} / v^{2}, R e=u l / v$. These formulas are put into Eq. (5) and a new equation can be developed as Eq. (6).

$$
\begin{aligned}
(h l)^{3 / 4} & =l\left[\frac{\eta r}{4\left(t_{s}-t_{w}\right)}\right]^{3 / 4}\left(\frac{4 g^{1 / 3} \lambda\left(t_{s}-t_{w}\right)}{58 P_{r w}^{1 / 4} P_{r s}^{(-3 / 4)} v^{2 / 3} \eta r}\right) \\
& +\left[\frac{\eta r}{4\left(t_{s}-t_{w}\right)}\right]^{3 / 4}\left(253-\frac{9200}{58 P_{r w}^{1 / 4} P_{r s}^{(-3 / 4)}}\right)
\end{aligned}
$$

Unlike Eq. (1), Eq. (6) shows a more complex relationship between the ACHTC and the characteristic length. It is almost impossible to get a proportion of the ACHTCs of the three kinds of cooling plates just by the ratio of the characteristic lengths of the three kinds of cooling plates. In 
Table 1: Parameters of condensation heat transfer on a square vertical plate

\begin{tabular}{lccc}
\hline Items & Parameters & Units & Values \\
\hline 1 & Vapor & - & $\mathrm{H}_{2} \mathrm{O}$ \\
2 & Vapor quality & - & 1 \\
3 & Vapor pressure & $\mathrm{Pa}$ & $1.013 \times 10^{5}$ \\
4 & Condensing temperature & ${ }^{\circ} \mathrm{C}$ & 100 \\
5 & Plate temperature & ${ }^{\circ} \mathrm{C}$ & 98 \\
6 & Width of plate & $\mathrm{m}$ & 0.3 \\
7 & Height of plate & $\mathrm{m}$ & 0.6 \\
\hline
\end{tabular}

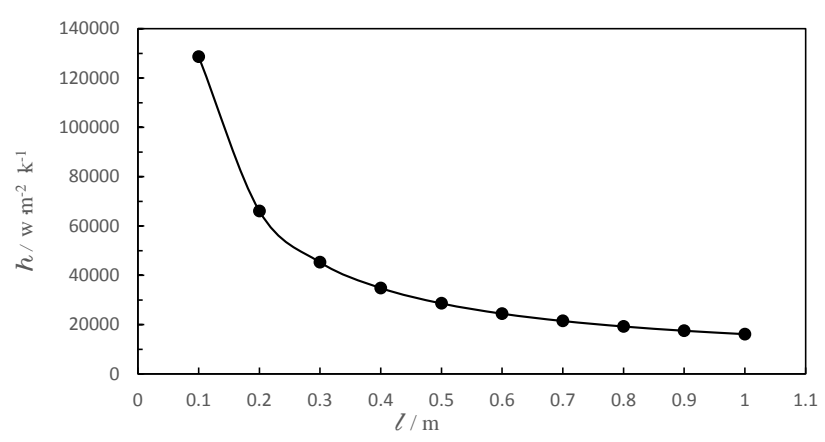

Figure 4: ACHTCs of water on vertical cooling plates with different height

order to solve this problem, direct substitution method is adopted. That means the parameters of a given condensing heat transfer condition are substituted in Eq. (6) and different $h$ values are calculated according to the different $l$ values. These parameters are given in Table 1 , and the calculation results are shown in Figure 4.

From Figure 4, it is clear that when $l$ is less than 0.3 $\mathrm{m}, h$ rapidly decreases with increasing of $l$, when $l$ is more than $0.3 \mathrm{~m}, h$ decreases slowly with increasing of $l$. In order to quantitatively compare the enhanced heat transfer performance of the LSCPs, the total wall height $l$ of the three kinds of plates, shown in Figure 3, are set at 5 different values, such as $0.4 \mathrm{~m}, 0.6 \mathrm{~m}, 0.8 \mathrm{~m}, 1.0 \mathrm{~m}, 1.2 \mathrm{~m}$. For each $l, h$ is calculated according to the parameters listed in Table 1. Calculated results are shown in Figure 5. Figure 5 shows that when $l=1.2 \mathrm{~m}, 1 \mathrm{~m}, 0.8 \mathrm{~m}, 0.6 \mathrm{~m}, 0.4 \mathrm{~m}$ respectively, $h$ of 2LSCP are $73 \%, 77 \%, 81 \%, 85 \%, 90 \%$ higher than that of CCP while $h$ of 3LSCP are 157\%, 159\%, 170\%, 186\% higher than that of CCP.

For turbulent flow, it can be concluded that the smaller the height of condensation area, the greater the ACHTC of a cooling plate, and the better the enhanced heat transfer performance. Moreover, under the same conditions, the enhanced heat transfer performance of a LSCP in turbulent flow is better than that in laminar flow.

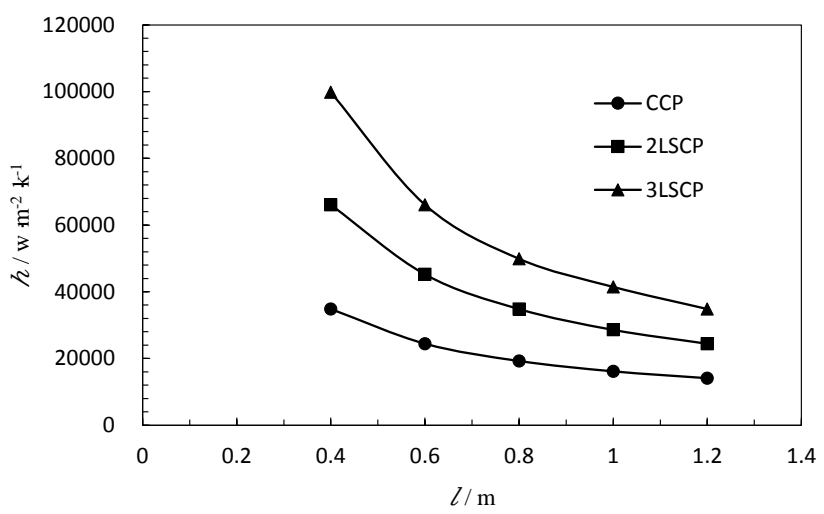

Figure 5: ACHTCs of water on CCP, 2LSCP and 3LSCP with different height

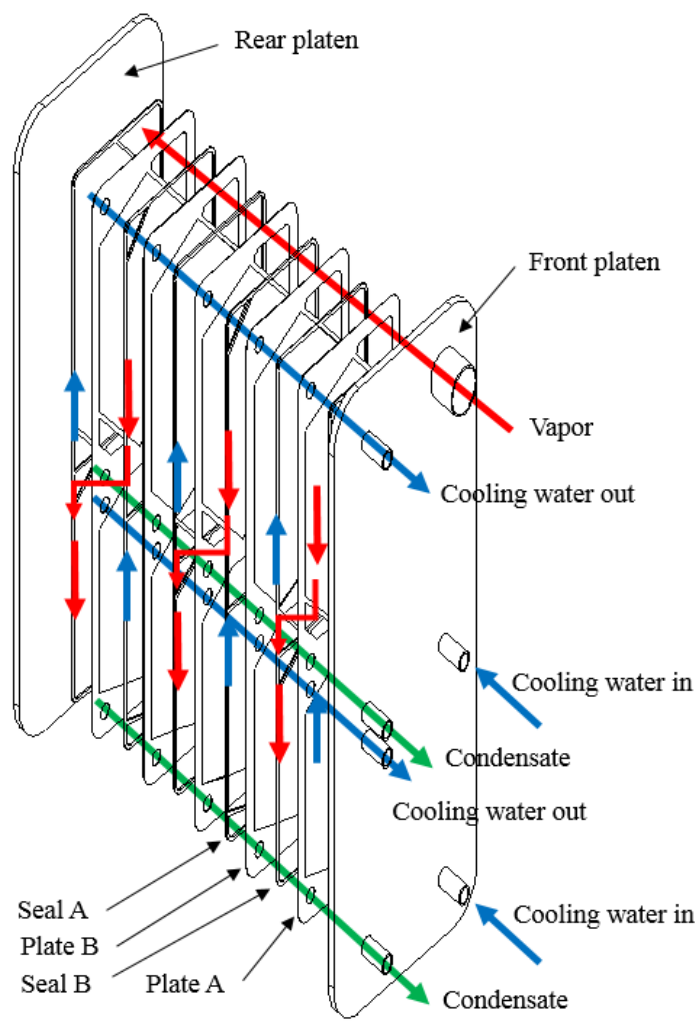

Figure 6: Assembly diagram of LVSPC

\section{Structural design of LVSPC}

The above theoretical analysis is based on flat surface, while the actual plate condenser consist of corrugated plates, because the fluid disturbance on the corrugated surface is more intense and the heat transfer performance is better [18]. Therefore, according to the basic structure of 2LSCP (see Figure 2), a liquid-vapor separation plate condenser (LVSPC) is designed in this paper. This condenser mainly consists of a set of LSCPs and seals. Figure 6 gives 


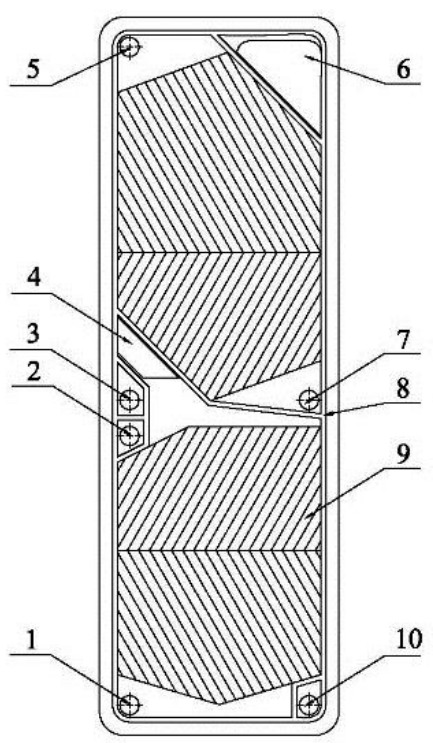

the front of plate $\mathrm{A}$

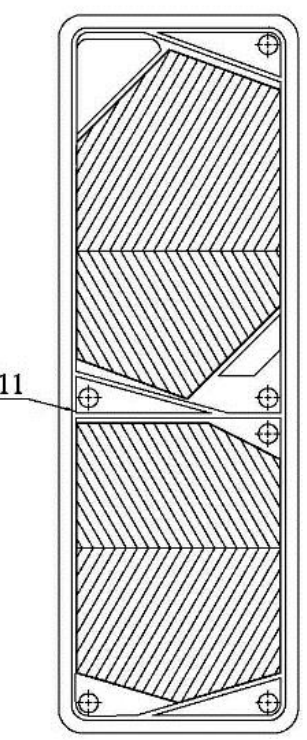

the back of plate $\mathrm{A}$

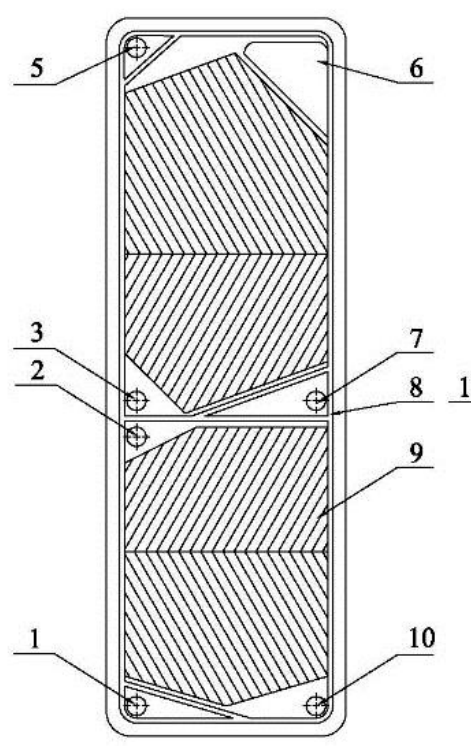

the front of plate $B$

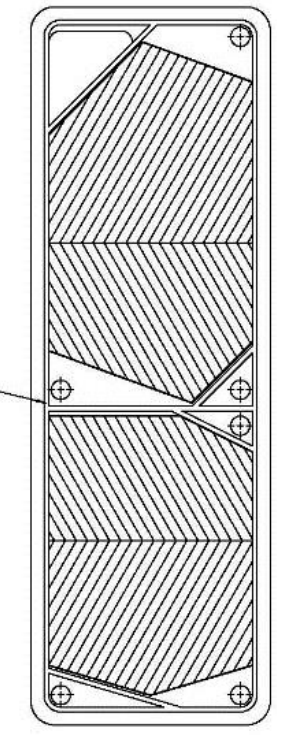

the back of plate $B$

1. the second condensate outlet, 2. the first cooling water outlet, 3. the first condensate outlet, 4.vent, 5. the second cooling water outlet, 6 . vapor inlet, 7. the second cooling water inlet, 8. seal A, 9. Herringbone board, 10. the first cooling water inlet, 11. seal B

Figure 7: Structure of plate A and plate B

the detailed assembly diagram. Figure 7 shows the structures of LSCPs (including plate A and plate B) used in this LVSPC. Plate A and plate B are symmetrical in shape and the same size. In addition, plate $A$ has a vent which allows the uncondensed vapor from the first condensing area into the second condensing area. Plate B does not have any vents. Some important sizes are listed in Table 2.

Similar to 2LSCP, there are two condensing areas in each plate $A$ and plate $B$, where the first condensing area is above the first condensate outlet, and the second condensing area is below that. Vapor from the vapor inlet enters the first condensing areas and then is cooled by the cooling water flowing in the next channel. Some vapor is condensed and the condensate is drained through the first condensate outlet. Consequently, a single vapor phase without condensate is allowed to occur in the second condensing area through the vent and is continued to be cooled. Finally, the vapor is completely condensed and the condensate flows out of the second condensing area from the second condensate outlet. In addition, an adjusting valve is installed in the first condensate outlet, and the opening of the adjusting valve is rationally controlled so as to generate a certain flow resistance, which can avoid the vapor leakage.
Table 2: Parameters of plate $A$ and plate $B$

\begin{tabular}{cccc}
\hline Items & Parameters & Units & Values \\
\hline 1 & thickness of plate & $\mathrm{m}$ & 0.0005 \\
2 & average space between plate A & $\mathrm{m}$ & 0.003 \\
& and B & & \\
3 & width of plate & $\mathrm{m}$ & 0.2 \\
4 & height & $\mathrm{m}$ & 0.6 \\
5 & Corrugation height & $\mathrm{m}$ & 0.0038 \\
6 & Corrugation pitch & $\mathrm{m}$ & 0.016 \\
7 & chevron angles & $\circ$ & 60 \\
8 & area of the plate & $\mathrm{m}^{2}$ & 0.032 \\
9 & enlargement factor & & 1.24 \\
10 & number of plates & & 20 \\
11 & number of plates effective in & & 18 \\
& heat transfer & & \\
12 & number of channels on & & \\
& refrigerant side & & \\
13 & number of channels on water & & \\
& side
\end{tabular}


Table 3: Operation conditions of the LVSPC

\begin{tabular}{|c|c|c|c|}
\hline Items & Parameters & Units & Condensing channel \\
\hline 1 & Fluid & - & R134a \\
\hline 2 & $\begin{array}{c}G \\
\text { (Inlet mass flux) }\end{array}$ & $\mathrm{kg} \cdot \mathrm{m}^{-2} \cdot \mathrm{s}^{-1}$ & $22,23,24,25,26,27,28,29,30,31,32$ \\
\hline 3 & $\begin{array}{c}T_{c} \\
\text { (condensation temperature) }\end{array}$ & ${ }^{\circ} \mathrm{C}$ & 40 \\
\hline 4 & $\begin{array}{c}X \\
\text { (Inlet vapor quality) }\end{array}$ & - & $0.5,0.6,0.7,0.8,0.9,1.0$ \\
\hline 5 & vent vapor quality & - & 1 \\
\hline
\end{tabular}

\section{Comparative computation of ACHTC of LVSPC}

\subsection{Experimental correlation and operation conditions}

In view of the popularity of plate condensers, a great deal of research on the heat transfer performance of plate condenser has been done recently [19]. According to these research results, two-phase heat transfer in PHEs is a function of various parameters such as the plate surface structure, heat flux, mass flux, vapor quality, film thickness, flow regime. Thus, it is more challenging to obtain a general correlation that would take into account the effects of all these parameters. Mancin et al. [20, 21], Wang et al. [22], Shah [23], Kuo et al. [24], Han et al. [25], Longo [26, 27] and Yan et al. [28] and so on have studied the heat transfer performance of some CPC. Based on the experimental data, they developed some experimental correlations for the condensation heat transfer of vapor in CPC. Among these experimental correlations, the one developed by Yan et al. is the most recognized. (See Eq. (7))

$$
h=4.118\left(\frac{k_{l}}{D_{h}}\right) R_{e e q}^{0.4} P_{r l}^{1 / 3}
$$

where: $R_{e e q}=\frac{G_{e q} D_{h}}{\mu_{l}}, G_{e q}=G\left[\left(1-x_{m}\right)+x_{m}\left(\frac{\rho_{l}}{\rho_{g}}\right)^{1 / 2}\right]$

In this study, a given CPC, whose size is the same as the LVSPC and just without liquid-vapor seperation, is taken as a contrast object to compare the ACHTC with the LVSPC under the same operation conditions (see Table 3). The ACHTCs are calculated by the experimental correlation developed by Yan et al. with EES (Engineering Equation Solver), which is an equation solving software applied in the field of engineering thermodynamics. Some of the current published work concluded that mass flux and vapor quality are the main affecting parameters for condensation heat transfer of PHEs [29-31]. Therefore, in Table 3, inlet mass flux and inlet vapor quality are set with a series of parameters in order to study their effects on the ACHTC of the LVSPC. To simplify the calculations, the following assumptions are made in this paper:

1. The fluid of plate condensers is one-dimensional homogeneous flow.

2. The vapor and liquid can be separated effectively in the first condensate outlet, and the vapor state parameters can be controlled.

3. The whole process of condensation remains saturated.

\subsection{Results and comparative analysis}

As the space is limited, the calculation processes are omitted and the results are directly presented in Figure 8 and Figure 9.

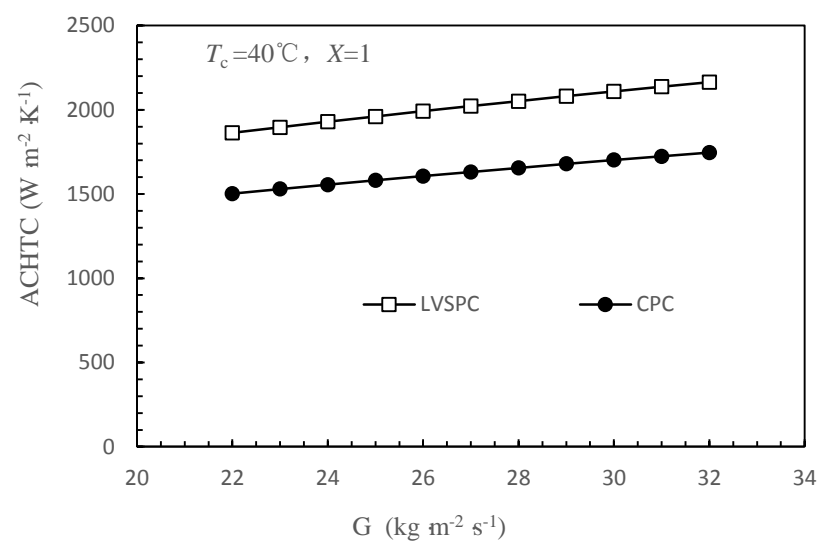

Figure 8: Effect of inlet mass flux on the ACHTCs 


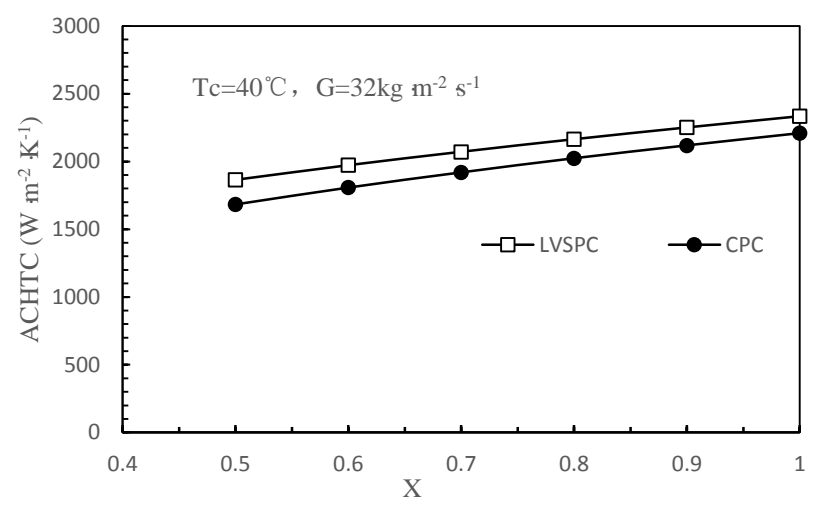

Figure 9: Effect of inlet vapor quality on the ACHTCS

\subsubsection{Effect of inlet mass flux on the ACHTC}

From the curve of LVSPC in Figure 8, it is concluded that the ACHTC of LVSPC increases in proportion to inlet mass flux. This conclusion is similar to the results of the given CPC (see the curve of CPC). This is because when the direction of the vapor flow is in the same direction as the downward flow of the condensate film, the vapor flow will stretch the condensate film. The larger the vapor mass flux, the thinner the condensate film and the better the thermal conductivity of the condensate film. Due to the thinner condensate film, the ACHTC of the LVSPC is about $24 \%$ higher than that of the given CPC at the same inlet mass flux.

\subsubsection{Effect of inlet vapor quality on the ACHTC}

Vapor quality is the mass fraction of dry vapor contained in wet vapor. The lower the vapor quality in a condenser, the more liquid droplets in the vapor, and the larger the liquid film thickness. Therefore, Figure 9 shows that the ACHTCs of both the LVSPC and the given CPC increase with an increase in inlet vapor quality. Because of faster liquid drainage and thinner liquid film, the ACHTC of the LVSPC is about $6 \%-11 \%$ higher than that of the given $\mathrm{CPC}$ at the same inlet vapor quality.

\section{Conclusion}

The basic structures of 2LSCP and 3LSCP are designed, and the ACHTCs of water on CCP, 2LSCP and 3LSCP are computed and compared respectively using Eq. (1) and Eq. (6). According to the basic structure of 2LSCP, the LVSPC is innovatively developed. The ACHTCs of the LVSPC with different operating parameters are calculated with the exper- imental correlation of Yan and compared with the ACHTCs of the given CPC. The following conclusions are drawn.

According to Eq. (1), for a laminar flow, the ACHTCs of 2SLCP and 3SLCP are respectively 19\% and 32\% higher than that of CCP under the same conditions. Accordingly, if a cooling plate is divided into $\mathrm{N}$ condensing areas (NLSCP), the ACHTC ratio of NLSCP to CCP is $\sqrt[4]{N}$, which implies that for a LSCP, the greater the number of condensing areas, the higher the ACHTC of LSCP.

According to Eq. (6), for a turbulent flow on a vertical cooling plate, it can be concluded that the smaller the height of condensation area, the greater the ACHTC, and the better the enhanced heat transfer performance. Moreover, under the same conditions, the heat transfer enhancement effect of LSCP in turbulent flow is better than that in laminar flow.

For the LVSPC, as can be seen from the curves in the figures, similar to CPC, the ACHTCs of the LVSPC are increased with the inlet mass flux and vapor quality and 6\%$24 \%$ larger than that of the given CCP at the same condition.

Acknowledgement: The authors gratefully acknowledge the financial support from the Guangzhou science and technology plan project (Grant No. 201704030108) under the title "Research and development of multi flow plate condenser based on micro channel liquid-vapor condensation".

\section{References}

[1] Huang J, Sheer TJ, Bailey-McEwan M. Heat transfer and pressure drop in plate heat exchanger refrigerant evaporators. Int I Refrig. 2012;35(2):325-35.

[2] Peng XF, Wu D, Zhang Y. Applications and principle of high performance condensers. Chemical Industry and Engineering Progress. 2007;26(1):97-104.

[3] Hua N. Investigation on the Optimisation Method and Application of Liquid-Vapor Separation Condensers. Doctoral Thesis 2018. Department of Materials and Energy, Guangdong University of Technology. Guanzghou, China.

[4] Tan K, Chen Y, Wu D. A Theoretical Analysis of the Capillary Effect on Liquid Vapor Separation. Journal of Guangdong University of Technology. 2012;29(4):90-5.

[5] Guo WX, Chen Y, Mo SP. Numerical simulation of two phase flow in manifold with perforated plate. Journal of Thermal Science and Technology. 2014;13(1):40-5.

[6] Mo S, Chen X, Chen Y, Yang Z. Effect of geometric parameters of liquid-gas separator units on phase separation performance. Korean J Chem Eng. 2015;32(7):1243-8.

[7] Hua N, Chen Y, Chen E, Deng L, Zheng W, Yang Z. Prediction and verification of the thermodynamic performance of vapor-liquid 
separation condenser. Energy. 2013;58:384-97.

[8] Chen Y, Hua N, Deng L. Performances of a split-type air conditioner employing a condenser with liquid-vapor separation baffles. Int J Refrig. 2012;35(2):278-89.

[9] Chen Y, Deng L, Luo X, Mo S. Energy and exergy analysis on a parallel-flow condenser with liquid-vapor separators in an R22 residential air-conditioning system. Heat Transf Eng. 2015;36(1):102-12.

[10] Zhong TM, Chen Y, Zheng WX, Hua N, Luo XL, Yang QC, et al. Experimental investigation on microchannel condensers with and without liquid-vapor separation headers. Int. J. Applied Thermal Engineering. 2014;73(2):1510-8.

[11] Zhong TM, Chen Y, Yang QC, Song M, Luo X, Xu J, et al. Experimental investigation on the thermodynamic performance of doublerow liquid-vapor separation microchannel condenser. Int J Refrig. 2016;67:373-82.

[12] Zhong TM, Chen Y, Hua H, Zheng WX, Luo X, Mo S. In-tube performance evaluation of an air-cooled condenser with liquid-vapor separator. Int. J. Applied Energy. 2014;136:968-78.

[13] Chen XQ, Chen Y, Deng LS, Mo SP, Zhang H. Experimental verification of a condenser with liquid-vapor separation in an air conditioning system. Int. J. Applied Thermal Engineering. 2013;51(1):48-54.

[14] Luo X, Xu J, Chen Y, Mo S. Mathematical optimization of the liquid separation condenser used in the organic Rankine cycle. Energy Procedia. 2015;75:3127-32.

[15] Luo X, Xu J, Chen Y, Mo S. Mathematical modelling and optimization of tht liquid separation condenser used in organic Rankine cycle. Appl Energy. 2017;185:1309-23.

[16] Nusselt W. The condensation of steam on cooled surfaces. Z.Ver. Deutsch. Ing. 60, 541-546, 569-575. (Translated into English by D. Fullarton. Chemical Engineering Fundamentals. 1916;1(2):619.

[17] Labuntzov DA. Heat transfer at film condensation of pure vapors on vertical surface and horizontal pipes [in Russion]. Int. J. Thermal Energy. 1957;7(1):72-82.

[18] Zhang GM, Tian MC, Zhou S. Simulation and analysis of flow pattern in cross-corrugated plate heat exchangers. J Hydrodynam. 2006;18(5):547-51.
[19] Radia E. Vikrant, Aute., Reinhard, Radermacher., A survey of correlations for heat transfer and pressure drop for evaporation and condensation in plate heat exchangers. Int J Refrig. 2016;65:1226.

[20] Mancin S, Del Col D, Rossetto L. Condensation of superheated vapour of R410A and R407C inside plate heat exchangers: experimental results and simulation procedure. Int J Refrig. 2012;35(7):2003-13.

[21] Mancin S, Del Col D, Rossetto L. R32 partial condensation inside a brazed plate heat exchanger. Int J Refrig. 2013;36(2):601-11.

[22] Wang L, Christensen R, Suden B. An experimental investigation of steam condensation in plate heat exchangers. Int. J. Heat Exch. 2000;1(2):125-50.

[23] Shah M. A general correlation for heat transfer during film condensation inside pipes. Int J Heat Mass Transf. 1979;22(4):54756.

[24] Kuo WS, Lie YM, Hsieh YY, Lin TF. Condensation heat transfer and pressure drop of refrigerant $\mathrm{R}-410 \mathrm{~A}$ flow in a vertical plate heat exchanger. Int J Heat Mass Transf. 2005;48(25-26):5205-20.

[25] Han D, Lee K, Kim Y. The characteristics of condensation in brazed plate heat exchangers with different chevron angles. J Korean Phys Soc. 2003;43(1):66-73.

[26] Longo GA, Righetti G, Zilio C. A new computational procedure for refrigerant condensation inside herringbone-type brazed plate heat exchangers. Int J Heat Mass Transf. 2015;82:530-6.

[27] Longo GA, Righetti G, Zilio C. A New Model for Refrigeration Condensation Inside a Brazed Plate Heat Exchanger (BPHE). Proceedings of the 15th International Heat Transfer Conference. Kyoto Japan. 2014; August 10-15.

[28] Yan Y, Lio H, Lin T. Condensation heat transfer and pressure drop of refrigerant R-134a in a plate heat exchanger. Int J Heat Mass Transf. 1999;42(6):993-1006.

[29] Kim I, Park J, Kwon Y, Kim Y. Experimental study on R-410A evaporation heat transfer characteristics in oblong shell and plate heat exchanger. Heat Transf Eng. 2007;28(7):633-9.

[30] Thonon B, Bontemps A. Condensation of pure and mixture of hydrocarbons in a compact heat exchanger: experiments and modelling. Heat Transf Eng. 2002;23(6):3-17.

[31] Palm B, Claesson J. Plate heat exchangers: calculation methods for single- and two-phase flow. Heat Transf Eng. 2006;27(4):8898. 